\title{
PERFILES
}

\section{ENTREVISTA A DAVID CABALLER, DIRECTOR DE ANIMACIÓN STOP-MOTION}

\author{
Raúl González Monaj
}

Universitat Politècnica de València

La entrevista a David Caballer nos acerca a un animador imprescindible a la hora de comprender la que fue y es la famosa animación valenciana de plastilina. A través de sus vivencias profesionales, recuerdos y reflexiones, desde sus inicios hasta el día de hoy, conoceremos de primera mano lo que significa ser un animador profesional. Veremos cómo la versatilidad, la adaptación al encargo y a las circunstancias caracterizan al animador actual y de calidad.
The interview with David Caballer brings to us an essential animator to understand which was and is Valencia's famous clay animation. Through his professional experiences, memories and reflections, from his beginnings to today, we will know firsthand what it means to be a professional animator. We'll see how the versatility, adaptation to the commissioned work and to the circumstances still characterize high qualified animators. 


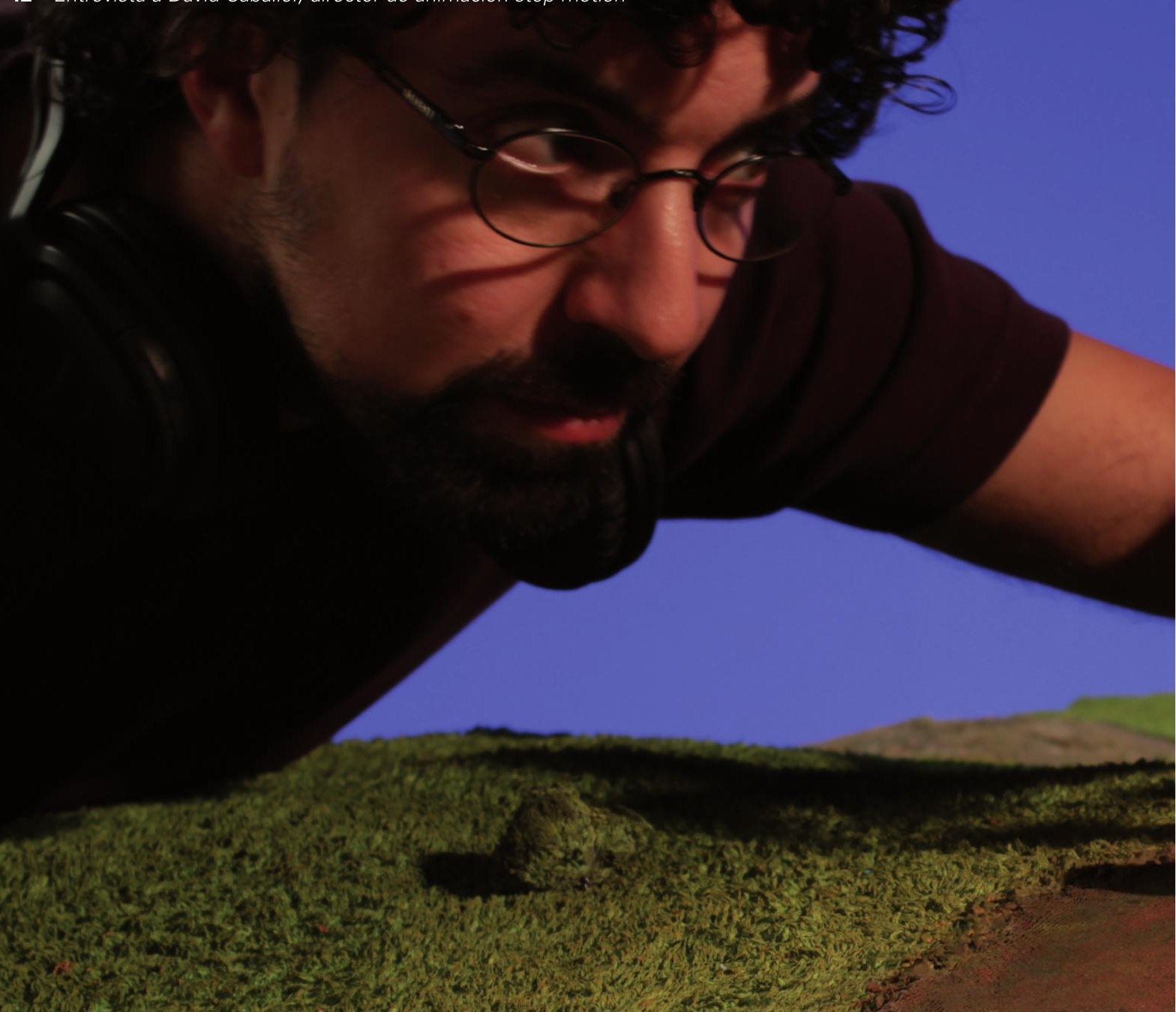

Fig. 2 - Animando una secuencia de Clay Kids

David Caballer es uno de los animadores de volúmenes más versátiles del panorama nacional, siendo capaz de animar con igual soltura tanto personajes de plastilina como de 3D infográfico. Tras su paso por las asignaturas de animación en la licenciatura de Bellas Artes se inicia en el mundo profesional del stop-motion, haciendo prácticas en la ya desaparecida Tiranosaurus Producciones. Pero es de la mano del célebre Pablo Llorens como consigue su primer trabajo oficial de animador para la serie Doc Franky (1999). Tras algunos encargos más cambia totalmente de técnica e inicia su andadura de animador 3D como miembro fundador de Somnis
Animació. Durante esta etapa infográfica, que se prolongará a lo largo de tres años, realizará multitud de trabajos publicitarios y dirigirá el galardonado El sueño de Pedro (2002). Simultanea estos trabajos como animador principal, con la última remesa de anuncios de la Campaña del Euro de Los García (2000). A partir de 2003 empieza su actual fase de animador autónomo, tanto de plastilina como de $3 \mathrm{D}$, en la que ha sido requerido entre otras producciones para $\mathrm{El}$ enigma del chico croqueta (Pablo Llorens, 2004), El ataque de los kriters asesinos (Sam, 2007), Vicenta (Sam, 2010) o Clay Kids (Javier Tostado), actualmente en producción. 


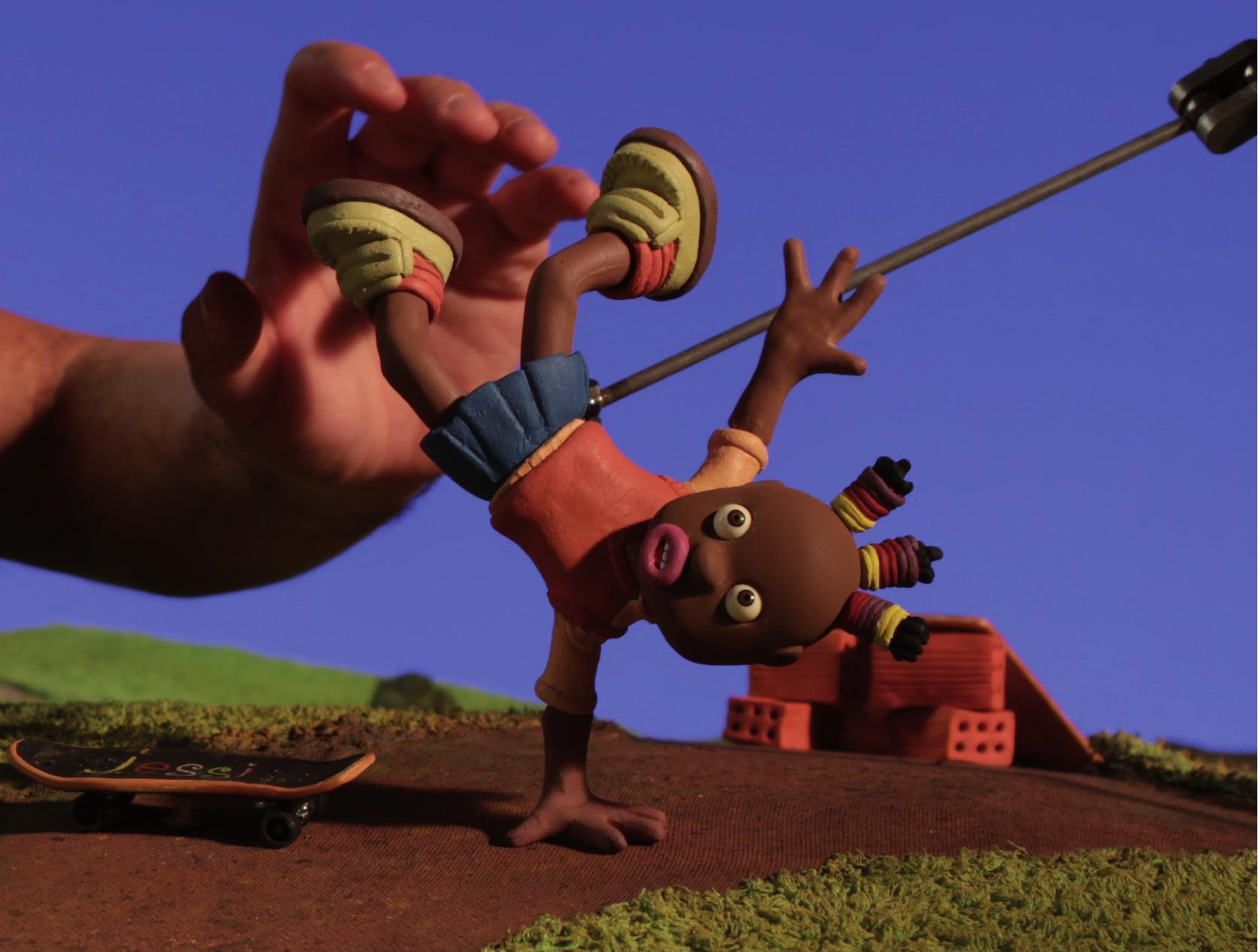

¿Cómo describirías tu aventura empresarial, cuando eras un recién licenciado en Bellas Artes? Cuéntanos un poco de tu experiencia en Somnis.

Pues visto desde la distancia, ahora entiendo que fue bastante arriesgado, porque quizás no teníamos la suficiente experiencia profesional como para embarcarnos en ese proyecto. Pero bueno, tampoco teníamos mucho que perder... Para mí fue fácil, porque Jesús Martínez, y Remi Hueso estaban creando la empresa, y yo sólo tuve que subirme al carro. Era un buen momento para la animación por ordenador, que estaba acabando de despegar, y a nosotros tres, bastante jóvenes e inocentes, nos sobraba ilusión y ganas de trabajar. Hicimos cosas muy interesantes en ese momento, pero los grandes encargos no llegaron nunca...

Tus primeros trabajos profesionales como animador stop-motion te llegaron de la mano de Pablo Llorens, ¿cómo influyó Pablo

en tus inicios?

Pues fue determinante, porque animar en una serie te permite coger mucha confianza 


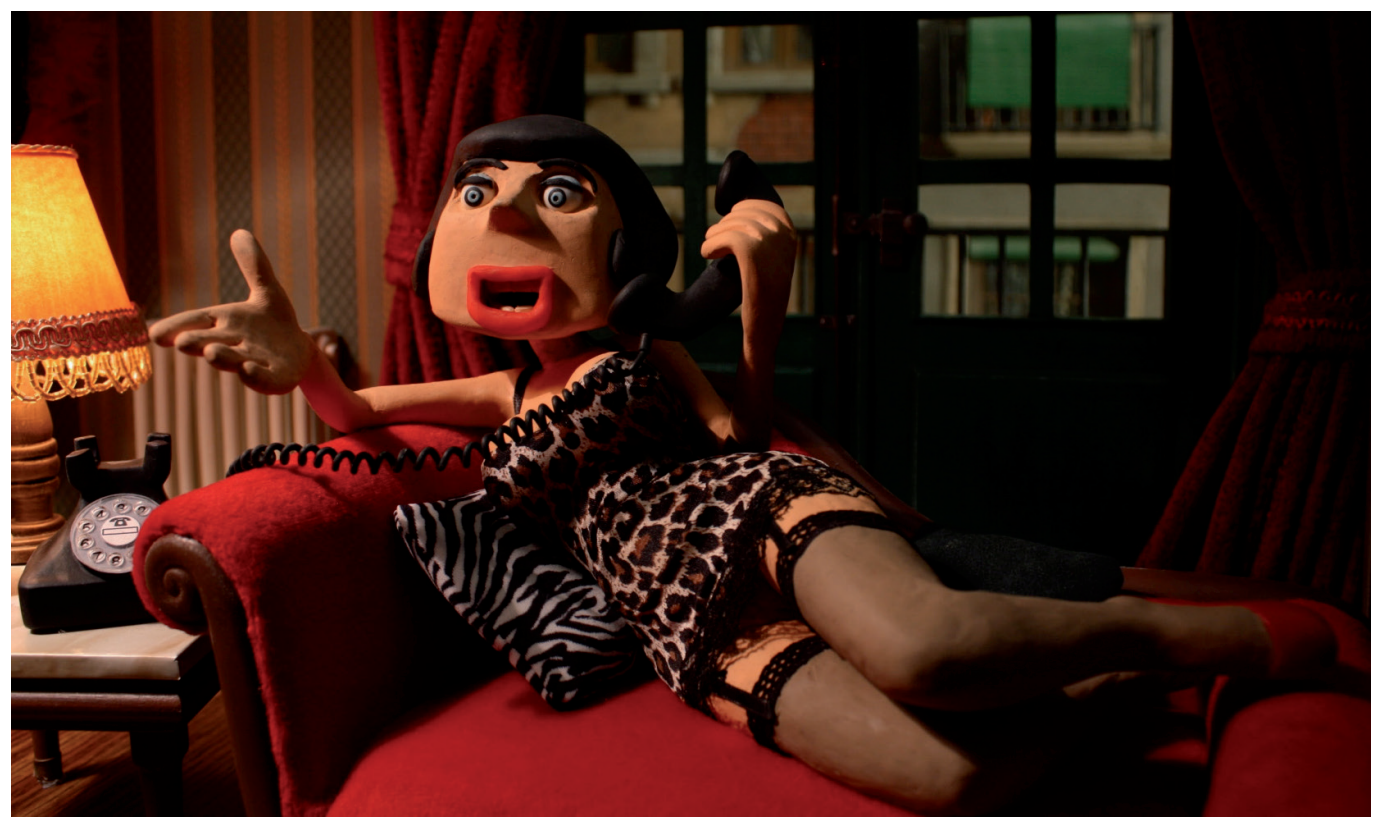

Fig. 3 - Carmen, uno de los personajes animados por David Caballer en la premiada Vicenta (Sam, 2010)

en tu trabajo, ya que animas muchas horas al día, y así todos los días, de manera que trabajar en Doc Franky fue una buena escuela. Y luego vinieron los anuncios de la campaña del Euro de los García, rodados en Madrid con un gran despliegue humano y técnico... Fue un trabajo que tuvo muchísima repercusión, a nivel de audiencia, porque los ponían una y otra vez en la tele. ¡Hasta me hacían entrevistas en la prensa saguntina! (je, je).

Es un placer que Pablo siga contando conmigo, de vez en cuando, si nuestras agendas nos lo permiten...

En tu carrera has ido de la animación stopmotion al 3D, y del 3D a la animación stopmotion. ¿Podría decirse que ambas se retroalimentan? ¿Qué diferencias encuentras entre ambas como animador de personajes?

La animación stop-motion es más directa, más inmediata: puedes coger el personaje con tus manos, y mover exactamente lo que quieras, y cuando haces la foto, eso ya está visto para sentencia y sólo puedes seguir para adelante. Pero el 3D no es tan físico: selecciona esto, tira de aquí, gira por allá, ve al "keyframe", vuelve, cambia de vista, etc, etc. $\mathrm{Y}$ esto hace el proceso más largo... Aunque con el 3D siempre puedes retocar, y cambiar cosas, claro.

Bueno, sólo es una opinión personal.

Has sido animador principal en producciones dirigidas por Sam, como por ejemplo The Werepig (2008) o Vicenta (2010). ¿Cuál de estas películas destacarías o con qué trabajo te has sentido más realizado, y por qué?

Vicenta es mi mejor trabajo como animador de plastilina. Ya mientras rodábamos, tenía la sensación de que el resultado iba a ser extraordinario.

Sam es un genio de la animación en plastilina, y trabajar con él significaba estar siempre 

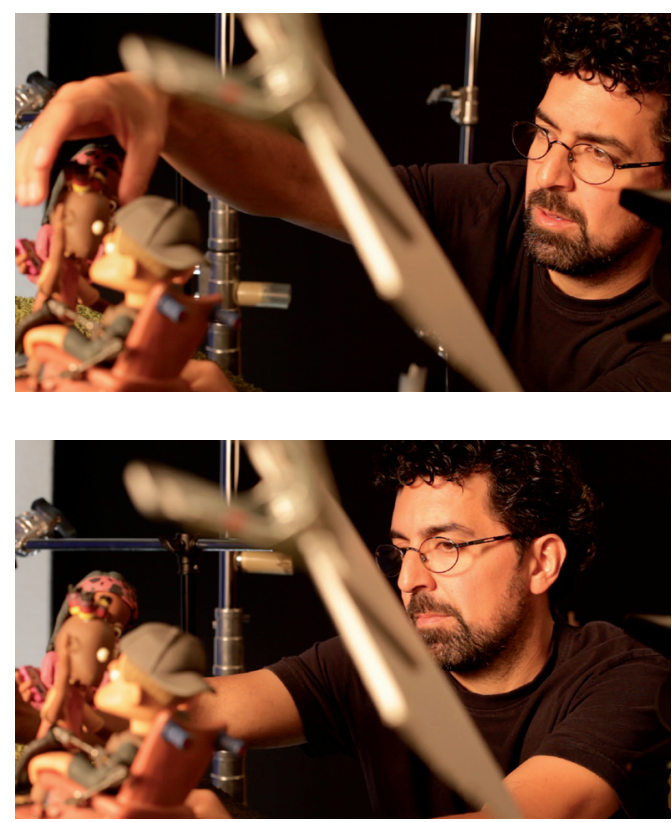

aprendiendo cosas. Lo malo es que la plastilina requiere mucho trabajo de modelado (la lucha contra la plastilina, lo llamo yo) y al final estás más tiempo modelando y refinando, que animando...

Según tu experiencia personal, ¿qué encuentras en la animación independiente $o$ en el cortometraje que no encuentras en la animación de encargo o comercial?

En los encargos hay un cliente final que lo paga todo y hay que darle lo que busca. Tiene que quedar contento con nuestro trabajo. Pero como en la animación independiente no existe ese cliente final, parece que no hay tanta presión...

Pero cuidado: los animadores nos debemos a los directores. ¿Qué quiero decir con esto? Que en realidad mi director es mi cliente, porque es a él a quien tengo que darle lo que busca, haya encargo o no, y es él quien tiene que quedar contento con mi trabajo.
Figs. 4 y 5 - David Caballer trabajando durante la exposición Stop Motion Don't Stop (2013)
¿Qué cualidades debería tener, en tu opinión, un buen animador de personajes stop-motion?

Mmmm... ¡Vaya pregunta complicada! Quizá lo más difícil es saber dominar al muñeco... Parece un chiste ¿verdad? Pero hace falta práctica para hacer con el muñeco exactamente lo que queremos hacer. Controlar las trayectorias, las poses, las distancias, etc. Siempre se ha hablado de paciencia, pero no creo que sea imprescindible.

$¿$ ¿ué destacas de tu trabajo en la producción de Clay Kids?

Clay Kids es el proyecto más grande en el que he trabajado jamás (iy el más largo!). Desde un primer momento Javier Tostado me nombró director de animación de la serie $-\mathrm{y}$ he de decir que me costó saber exactamente qué significaba eso... - . Javier buscaba un estilo de animación 
más dinámico que al que yo estaba acostumbrado, y me costó un poco llegar a entenderlo, pero creo que lo conseguimos. Y bueno, ha sido un verdadero placer trabajar con todos los animadores, y es que no han dejado de sorprenderme cada día, iporque cada día aprendía cosas nuevas con ellos! También le debo a Javier la decisión de ponerme dirigir episodios. Ha sido un paso más allá en mi carrera, tener a todo un equipo de profesionales a tus órdenes para hacer que tus capítulos sean una realidad, es una cosa especial.

¿Desde que acabaste tus estudios también has ejercido de docente y formador de animadores, como recientemente en los talleres de Clay Kids. ¿Qué es lo más gratificante de esta experiencia?

Lo más gratificante es ver progresar a los alumnos y ver cómo ellos mismos disfrutan de sus progresos. Verlos felices porque mejoran cada día. Y cómo yo también aprendo con ellos, porque yo no soy profesor de carrera, y claro, al tener que dar clase, me di cuenta de que muchas cosas que hacía al animar las hacía instintivamente, o por inercia, o que simplemente nunca me había parado a pensar cómo las hacía. Tuve que analizarme a mí mismo, y sacar conclusiones para poder transmitirlo a los alumnos. ¡Y eso me vino muy bien!

¿Cómo valoras el panorama actual de producción de stop-motion en nuestro país? (Pregunta difícil y comprometida...)

El stop-motion siempre ha estado ahí, medio escondido, pero vivo, y aunque parecía que se podía perder, es ahora cuando en España se han hecho los proyectos más grandes y ambiciosos. Eso es bueno, porque, nadie sabe lo que nos deparará el futuro... La verdad es que ahora la

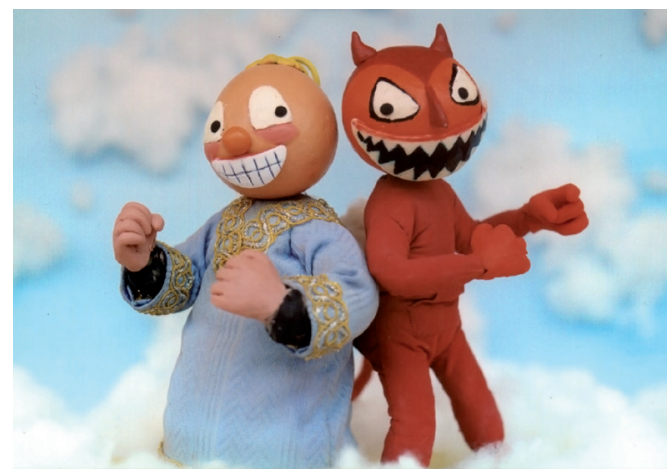

Fig. 6 - Àngel i dimoni (1998), primer trabajo de stop-motion realizado por David como estudiante en la Facultad de Bellas Artes de Valencia

tecnología nos lo ha puesto más fácil que nunca. De todas formas, yo creo que el sector de la producción audiovisual es un sector muy difícil, y la animación no va a ser diferente.

Por último, ¿qué consejo darías a un recién licenciado que desee introducirse profesionalmente en el mundo de la stop-motion?

Que anime muchos planos, que practique, porque la práctica es el mejor camino. Tenemos que sacar de nuestro interior todos los planos malos para que empiecen a salir los buenos. $\mathrm{Y}$ con esos planos, que se prepare una buena demo, porque una "reel" es la mejor carta de presentación para buscar trabajo.

(C) Del texto: David Caballer, Raúl González Monaj

(C) De las imágenes: Figs. 1, 2, 4 y 5, Clay Kids; Fig. 3, Conflictivos Productions; Fig. 6, David Caballer. 


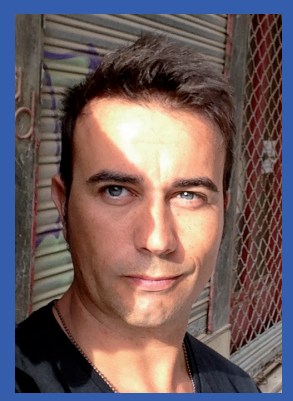

\section{Biografia}

Raúl G. Monaj es profesor de diversas asignaturas relacionadas con la animación en el Grado de Comunicación Audiovisual y en el Máster en animación de la UPV. Especializado en la preproducción comercial ha participado como profesional en cerca de una veintena de series animadas para televisión (Cuttlas, Discworld, 2020, Bugwatch, Captain Pugrwash, Little Grey Rabbit), en varios largometrajes ( $E l$ Cid, The reporter), así como en diversos anuncios publicitarios, tanto animados como de imagen real (Heineken, Nestlé, L'Oceanografic, Mc. Donalds). Es autor del libro Manual para la realización de storyboards.

\section{E-mail}

raugonmo@har.upv.es 